\title{
In-Situ FTIR Study of Heterogeneous Oxidation of SOA Tracers by Ozone
}

\author{
Runhua Wang, Yajuan Huang, Qian Hu, Gang Cao* and Rongshu Zhu \\ Shenzhen Key Laboratory of Organic Pollution Prevention and Control, Harbin Institute of Technology (Shenzhen), Shenzhen, \\ China
}

Secondary organic aerosols (SOA) play an important role in global climate change and air quality, and SOA tracers can directly characterize the source and reaction mechanism of SOA. However, it is not well known that whether the tracers can be oxidized or how the instability of the tracers in the atmosphere. In this paper, in-situ FTIR was used to analyze the chemical structure changes of erythritol, analogue of 2-methyl erythritol (AME) that is, a tracer of isoprene SOA, and 2, 3-dihydroxy-4-oxopentanoic acid (DHOPA), a tracer of toluene SOA, when exposed to high concentration of ozone for short periods. Under the condition of $20 \mathrm{ppm}$ ozone exposure for $30 \mathrm{~min}$, the change rate of absorption area of AME

\section{OPEN ACCESS}

Edited by:

Fudong Liu,

University of Central Florida,

United States

Reviewed by:

Giovanni Cagnetta,

Tsinghua University, China

Biwu Chu,

Research Center for EcoEnvironmental Sciences (CAS), China Tu Binh Minh,

VNU University of Science, Vietnam

*Correspondence: Gang Cao caogang@hit.edu.cn

Specialty section: This article was submitted to Organic Pollutants,

a section of the journal

Frontiers in Environmental Chemistry

Received: 28 June 2021 Accepted: 14 October 2021 Published: 29 October 2021

Citation:

Wang $R$, Huang $Y, H u Q$, Cao G and Zhu R (2021) In-Situ FTIR Study of Heterogeneous Oxidation of SOA Tracers by Ozone.

Front. Environ. Chem. 2:732219. doi: 10.3389/fenvc.2021.732219 at 3,480 and $1700 \mathrm{~cm}^{-1}$ was -0.0134 and $0.00117 \mathrm{int} . a b s / \mathrm{s}$, respectively, and the change rate of the absorption area of DHOPA at 1,640 and $3340 \mathrm{~cm}^{-1}$ was -0.00191 and 0.00218 int.abs/s, respectively. The pseudo-first-order reaction rate constant $k_{a p p}$ were $1.89 \times 10^{-8}$ and $2.12 \times 10^{-7} \mathrm{~s}^{-1}$, and the uptake coefficients of ozone on the surface of AME and DHOPA were $(1.3 \pm 0.8) \times 10^{-8}$ and $(4.5 \pm 2.7) \times 10^{-8}$, respectively. These results showed the oxidation processes of $\mathrm{AME}$ and DHOPA were slow in the presence of high concentrations of ozone, which implied that AME and DHOPA could be considered to be stable in the atmospheric environment with ozone as the main oxidant.

Keywords: SOA tracers, in-situ FTIR, ozone, uptake coefficient, pseudo-first-order reaction 2

\section{INTRODUCTION}

Organic tracers have been used widely for source apportionment of organic aerosols under the assumption that they are not reactive in the atmosphere (Katrib et al., 2005; Kleindienst et al., 2007; Ding et al., 2012; Lai et al., 2014). However, previous studies have indicated that some of those tracers may not remain stable, which leads to the inaccurate estimation of source contributions (And and Smith, 2004; Weitkamp et al., 2008a; Hoffmann et al., 2010; Lambe et al., 2012; Wang et al., 2020). Weitkamp et al. studied the ozone oxidation of primary organic tracers of cooking oil emission (oleic acid, palmitoleic acid, and cholesterol etc.) through a series of chamber experiments. The results showed that the rate constant of ozone heterogeneous oxidation of oleic acid was $1.5 \times 10^{-11} \mathrm{~cm}^{3}$ molec$^{-1} \mathrm{sec}^{-1}$, which was ten times of cholesterol and four times of palmitoleic acid (Weitkamp et al., 2008b). Lambe et al. studied the effective reaction rate of oxidation reaction of norhopane, an organic tracer of motor oil by hydroxyl radical, and the rate constant of norhopane was $8.4 \times 10^{-12} \mathrm{~cm}^{3}$ molec $^{-1} \mathrm{~s}^{-1}$ (Lambe et al., 2009). The study of Hennigan et al. indicated that rate constant of levoglucosan was $1.1 \times 10^{-11} \mathrm{~cm}^{3}$ molecule $\mathrm{s}^{-1}$ when biomass burning particles were exposed to $1 \times$ $10^{6}$ molecules $\mathrm{cm}^{-3}$ of $\mathrm{OH}$ (Hennigan et al., 2010).

The above studies were focused on the heterogeneous oxidation of primary organic tracers, while such investigations on the secondary organic tracers have seldom been reported. And there is no clear conclusion about the complexity of heterogeneous oxidation of secondary tracers. Kessler et al. used 
the erythritol as a surrogate for 2-methyltetrols and studied heterogeneous oxidation of pure erythritol particles by gasphase $\mathrm{OH}$ radicals with an effective $\mathrm{OH}$ uptake coefficient, $\gamma_{\text {eff, of }} 0.77 \pm 0.1$ and a corresponding chemical lifetime of $\sim 13.8 \pm 1.4$ days at a relative humidity $(\mathrm{RH})$ of $30 \%$ (Kessler et al., 2010). However, $\mathrm{Xu}$ et al. investigated the heterogeneous $\mathrm{OH}$ oxidation of pure erythritol aerosols that contained erythritol and ammonium sulfate (AS) at different dry inorganic-to-organic mass ratios (IOR) in an aerosol flow tube reactor at a high relative humidity of $85 \%$. Their kinetic data would suggest that 2methyltetrols in atmospheric particles were likely chemically stable against heterogeneous $\mathrm{OH}$ oxidation under humid conditions ( $\mathrm{Xu}$ et al., 2020).

The laboratory studies on atmospheric heterogeneous oxidation reactions, using Knudsen cell (Seisel et al., 2006; Zhou and Wang, 2014), flow tube reactor (Lelièvre et al., 2004; Kessler et al., 2010), FTIR (Zeng et al., 2013; He et al., 2016), smog chamber (Lee et al., 2004; Hartz et al., 2007; Weitkamp et al., 2007; Ge et al., 2016), have developed rapidly in the determination of kinetic constants of trace gases and adsorption reactions on particle surfaces (Lee and Harris, 2006; Goldstein et al., 2008; Nieto et al., 2008; He and Zhang, 2019). In recent years, in-situ FTIR technology has been widely used in heterogeneous oxidation studies of various compounds by monitoring functional group transformation as reactions progressed (Zeng et al., 2013; He et al., 2016; Gao et al., 2019). The evolution of the FTIR absorption peak with time is generally used to estimate the uptake coefficient, which refers to the fraction of gaseous oxidants irreversibly reacted in the surface of compounds after collision (Hudson et al., 2001; Smith et al., 2002; Hung et al., 2005). It is an important physicochemical parameter to characterize the heterogeneous reaction in the atmosphere, and an important quantitative index for the surface uptake ability of atmospheric particles (Moise and Rudich, 2002; Thornberry and Abbatt, 2004; Ziemann, 2005; Hung and Tang, 2010). The heterogeneous reaction rate between gaseous oxides and the condensed compounds can be calculated based on a pseudofirst-order rate equation with the corresponding uptake coefficient (Worsnop et al., 2002). Gao et al. studied the heterogeneous reactions of ozone with oleic acid via a flow system combined with ATR-FTIR, and reported the uptake coefficient $\gamma$ of ozone on oleic acid was $(4.6 \pm 1.0) \times 10^{-4}$ (Gao et al., 2019). The uptake coefficients of ozone on oleic acid in previous studies ranged from $(7.8 \pm 2) \times 10^{-3}$ to $(1.9 \pm 0.6) \times$ $10^{-5}$ (Hartz et al., 2007; Hearn and Smith, 2004; Nash et al., 2006; Smith et al., 2002; Rosen et al., 2008).

In this paper, in order to study the ozone heterogeneous oxidations of Erythritol, Analogue of 2-Methyl Erythritol (AME) and 2, 3-Dihydroxy-4-oxopentanoic Acid (DHOPA) which are secondary organic tracers of the largest natural source of non-methane hydrocarbons (isoprene) and the representative precursor of anthropogenic SOA (toluene) respectively, an in-situ FTIR was used to analyze the chemical structure changes of AME and DHOPA, when exposed to high concentrations of ozone for short periods. The uptake coefficients of ozone on the surface of AME and DHOPA were measured and the pseudo-first-order reaction rate constant of AME and DHOPA were estimated.

\section{MATERIALS AND METHODS}

\section{Materials and Instruments}

All chemicals used for this study had purity levels greater than 99\%. -AME was supplied by Aladdin, and DHOPA was supplied by TRC. Ozone was generated photolytically using a Xonics ozone generator (Jelight Model 600, Irvine, CA) and the ozone concentration was measured with a photometric ozone detector (2BTechnologies Model 106L). The experiment was carried out at room temperature, in that low constant temperature water baths (DHC-0505-A, qiwei), which controlled the temperature of ambient chamber at $25^{\circ} \mathrm{C}$. Analyses of heterogeneous oxidation of the AME and DHOPA were carried out in an in-situ FTIR (Is50FT-IR, Thermo). The in-situ FTIR was composed of a reaction chamber and a Harrick Praying Mantis. The reaction chamber consisted of an ambient chamber and a dome which equipped with two round $\mathrm{KBr}$ observation windows. The external facilities of the Harrick Praying Mantis included observation windows, purge door and purge line fitting, as well as two tilted mirrors and four horizontal mirrors in the Praying Mantis.

Figure 1 showed the experimental setup for measuring the uptake coefficients of ozone on the surface of AME or DHOPA solid powder using in-situ FTIR. The general procedures of the experiments were briefly outlined below: Firstly, a transmittance spectrum with the Praying Mantis in the sample compartment was collected when the wavenumber at $2,500 \mathrm{~cm}^{-1}$ reached the maximum value. Then, dry air was blown for $5 \mathrm{~min}$, and the background was collected. Finally, $1 \mathrm{mg}$ AME/DHOPA solid powders were spread out evenly at the bottom of the sample cup of the ambient chamber, and 20 ppm ozone was injected for 30 min continuously. The characteristic infrared absorption peaks of surface of solid powder during the process of the ozone oxidation of AME or DHOPA were monitored online under the FTIR operational conditions of the infrared resolution of $4 \mathrm{~cm}^{-1}$, the background scanning of 64 times, the series sample scanning of 32 times, the sample interval of $41.27 \mathrm{~s}$, and the scanning range of $4,000-400 \mathrm{~cm}^{-1}$. After each experiment completed, the residual ozone in the ambient chamber was removed by blowing dry air through the outlet.

\section{Calculation of Uptake Coefficient}

The method used to measure the uptake coefficients in this work was similar to that used in previous studies on ozone oxidations of oleic acid and linoleic acid (Jaoui et al., 2004; Hung et al., 2005; Engelke et al., 2010). Zeng et al. studied the heterogeneous reaction of linoleic acid with ozone. It was confirmed that the rate constant of linoleic acid oxidation was in accordance with the pseudo-first-order reaction rate constant. When the sample was exposed to $250 \mathrm{ppb}$ ozone concentration at $30 \% \mathrm{RH}, k_{a p p}$ was 5.98 $\times 10^{-4} \mathrm{~s}^{-1}$ and the uptake coefficient was $5.79 \times 10^{-4}$ (Zeng et al., 2013).

In our experiments, the molar ratio of ozone to AME or DHOPA remained at more than three orders of magnitude. 


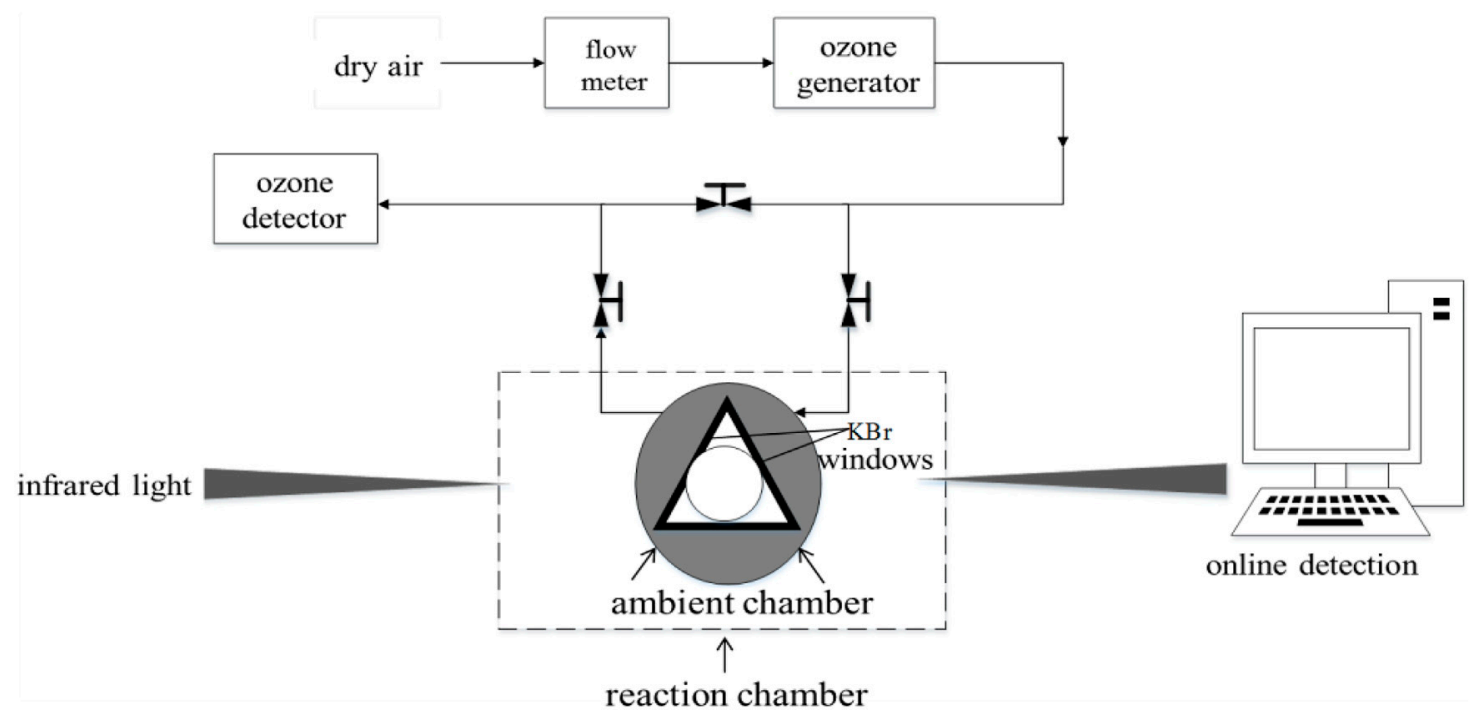

FIGURE 1 | in-situ FTIR experimental setup.

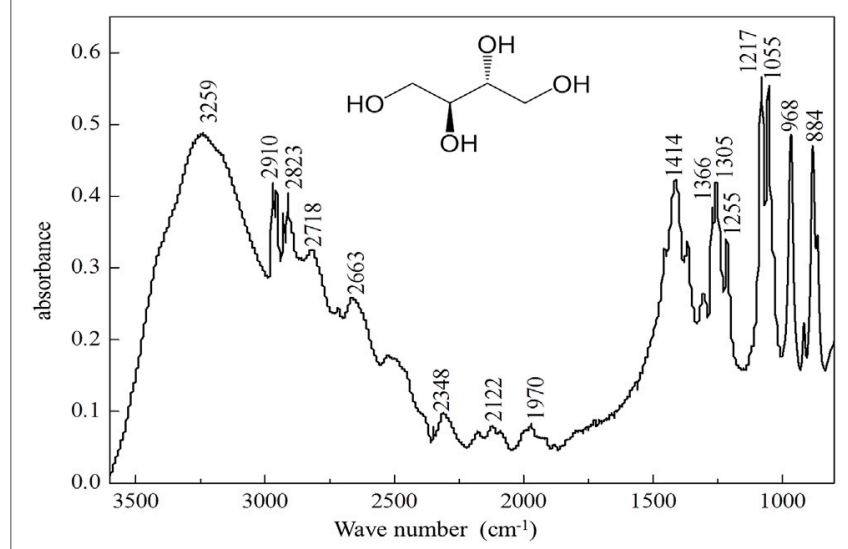

FIGURE 2 | Infrared spectrum of AME at room temperature.

Under such pseudo-first order reaction, the second-order reaction of ozone (as A in Eq. 1) and AME or DHOPA (as B in Eq. 1) can be considered as the pseudo-first-order reaction, the rate constant for which can be calculated by Eq. 2 (Gao et al., 2019).

$$
\mathrm{A}+\mathrm{B} \rightarrow \mathrm{P}
$$

$$
\frac{d[B]}{d t}=\mathrm{k}_{\mathrm{app}}[B] \text { when } k_{a p p}[\mathrm{~B}]=k[A][B]
$$

$k_{a p p}$ - Pseudo-first-order rate constant $\left(\mathrm{s}^{-1}\right)$;

$k-$ Second order rate constant $\left(\mathrm{cm}^{3} \cdot\right.$ molecule $\left.^{-1} \cdot \mathrm{s}^{-1}\right)$;

The uptake coefficient $\gamma$ was calculated using the change rate of the integral area of characteristic absorption peaks at specific wavelengths of AME or DHOPA based on Eq. 3 (Worsnop et al., 2002; Gao et al., 2019).

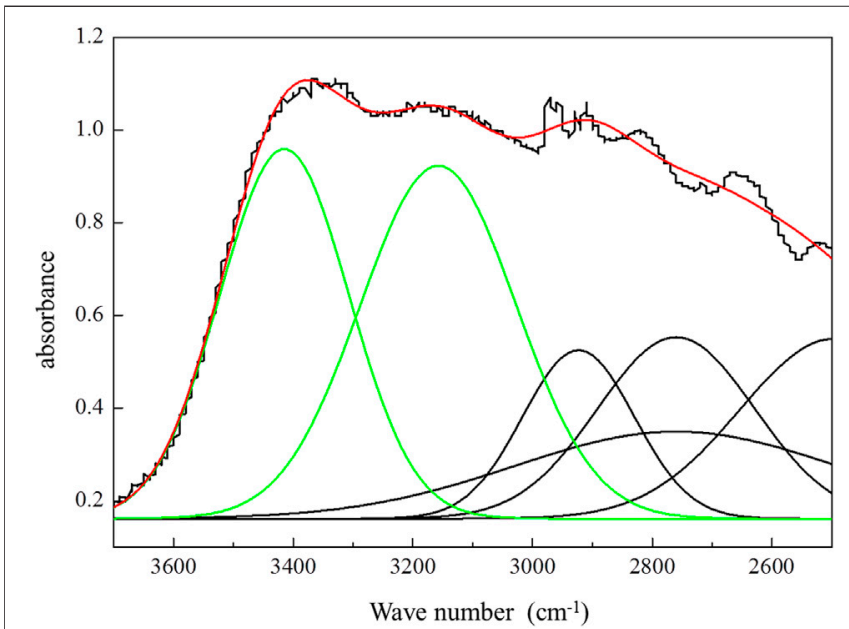

FIGURE 3 | Gaussian fitting results of AME in the 3,700-2500 $\mathrm{cm}^{-1}$ region.

$$
\frac{d\left[C_{i}^{a}\right]}{d t}=-\gamma\left(\mathrm{N}_{A} \frac{\mathrm{P}_{\mathrm{O}_{3}} \overline{\mathrm{c}}}{4 \mathrm{RT}}\right) \frac{\mathrm{S}_{\mathrm{A}}}{\mathrm{V}}
$$

$\left[C_{i}^{a}\right]$ the initial concentration of $\mathrm{i}\left(\right.$ molecules $\left.\cdot \mathrm{cm}^{-3}\right)$; $d\left[C_{i}^{a}\right]_{\mathrm{dt}}$ the rate of molecular change of $\mathrm{i}\left(\right.$ molecules $\left.\cdot \mathrm{cm}^{-3} \cdot \mathrm{s}^{-1}\right)$; $\overline{\mathrm{c}}$ - average rate of ozone in the gas phase $\left(\mathrm{cm} \cdot \mathrm{s}^{-1}\right)$;

$\mathrm{N}_{\mathrm{A}}$ — Avogadro's number $\left(6.02 \times 10^{23}\right.$ molecules $\left.\cdot \mathrm{mol}^{-1}\right)$;

$\mathrm{P}_{\mathrm{O}_{3}}$ atmospheric pressure of ozone $\left(\mathrm{Pa}=\mathrm{kg} \cdot \mathrm{m}^{-1} \cdot \mathrm{s}^{-2}\right)$;

$\mathrm{R}-$ gas constant or proportionality constant $\left(8.314 \mathrm{~J} \mathrm{~mol}^{-1} \mathrm{~K}^{-1}\right)$;

$\mathrm{T}$ - temperature $(\mathrm{K})$;

$\frac{S_{A}}{V}-$ the specific surface area of $\mathrm{i}\left(\mathrm{cm}^{-1}\right)$.

In this study, the surface area of the reaction chamber $\left(20 \mathrm{~cm}^{-1}\right)$ was assumed as the specific surface area for collision. However, the collision area corresponds to the 
TABLE 1 | IR frequencies and assignments for functional groups in AME.

\begin{tabular}{ll} 
Wavenumber $\left(\mathbf{c m}^{-\mathbf{1}}\right)$ & \multicolumn{1}{c}{ Band assignment } \\
\hline 3259 & $-\mathrm{OH}$ stretching \\
2910 & $-\mathrm{CH}_{2}$ antisymmetric stretching \\
2823 & $-\mathrm{CH}$ stretching \\
2718 & $-\mathrm{CH}_{2}$ symmetric stretching \\
2663 & $-\mathrm{CH}$ Stretching \\
2348 & Carbonyl $(\mathrm{C}=\mathrm{O})$ \\
2122 & Carbonyl $(\mathrm{C}=\mathrm{O})$ \\
1970 & Carbonyl $(\mathrm{C}=\mathrm{O})$ \\
1414 & Deformation of $\mathrm{C}-\mathrm{O}-\mathrm{H}$ \\
1366 & Deformation of $\mathrm{C}-\mathrm{O}-\mathrm{H}$ \\
1305 & $-\mathrm{OH}$ in-plane \\
1255 & $-\mathrm{OH}$ in-plane \\
1217 & $\mathrm{C}-\mathrm{C}$ Stretching \\
1055 & $\mathrm{C}-\mathrm{O}$ Stretching \\
968 & Deformation of $\mathrm{C}-\mathrm{H}$ \\
884 & Deformation of $\mathrm{C}-\mathrm{H}$
\end{tabular}

sample preparation methods and affects the uptake coefficient. In order to distinguish the changes of FTIR absorption peaks during the process of the oxidation reactions, enough amounts of samples was used, resulting in the formation of pores within the solid powder for ozone to permeate. As a result, our experiments measured the upper bounds of the uptake coefficients of AME and DHOPA.

\section{RESULTS AND DISCUSSION}

\section{Ozone Oxidation of AME}

Figure 2 showed the infrared spectrum of $\mathrm{AME}$ at a room temperature of $25^{\circ} \mathrm{C}$ and $30 \% \mathrm{RH}$.

To resolve the broad $\mathrm{O}-\mathrm{H}$ stretching band of carboxyl groups that was superimposed on the peaks of interest between 3,700 and
$2,500 \mathrm{~cm}^{-1}$, the six superimposed peaks were separated by 8.5 origin Gaussian fitting, including the stretching bands of $-\mathrm{OH}$ at $3,180 \mathrm{~cm}^{-1}$ and $3,480 \mathrm{~cm}^{-1},-\mathrm{CH}_{2}$ antisymmetric stretching at $2,910 \mathrm{~cm}^{-1},-\mathrm{CH}$ stretching at $2,823 \mathrm{~cm}^{-1},-\mathrm{CH}_{2}$ symmetric stretching at $2,718 \mathrm{~cm}^{-1}$, and $-\mathrm{CH}$ stretching at $2,663 \mathrm{~cm}^{-1}$, as shown in Figure 3 (Injae et al., 1998; Luo et al., 2003; Branca et al., 2016). The detailed assignment of spectral bands for AME was summarized in Table $\mathbf{1}$.

The heterogeneous oxidation of ozone on AME was carried out in a reaction chamber of FTIR under the same ambient conditions. The FTIR spectra of the AME were recorded as a function of time. Figure $\mathbf{4 A}$ showed that the area of the absorption peak at wavenumber $3480 \mathrm{~cm}^{-1}$ (-OH stretching) decreased with time when exposed to ozone. In addition, a small absorption peak at $1700 \mathrm{~cm}^{-1}$ appeared and the area of this peak increased with time, as shown in Figure 4B. It was likely the infrared absorption caused by the $\mathrm{C}=\mathrm{O}$ stretching of the reaction product. Changes in $\mathrm{AME}$ absorption peaks at $3,480 \mathrm{~cm}^{-1}$ and at $1700 \mathrm{~cm}^{-1}$ during the experiments indicated that $-\mathrm{OH}$ at the end chain of AME was oxidized to $\mathrm{C}=\mathrm{O}$ bond by ozone. Based on the changes in the absorption peak area at 3,480 and $1700 \mathrm{~cm}^{-1}$, the change rates of peak areas were calculated as -0.00134 int. abs/s and 0.00117 int. abs/s, respectively.

\section{Ozone Oxidation of DHOPA}

The infrared spectrum of DHOPA at a room temperature of $25^{\circ} \mathrm{C}$ and 30\% relative humidity was presented in Figure 5. To resolve the broad $\mathrm{O}-\mathrm{H}$ stretching band of alcohol $\mathrm{OH}$ and carboxylic acid -OH that were superimposed on the peaks of interest between 4,000 and $3,000 \mathrm{~cm}^{-1}$, as well as the peaks between 1800 and $1,600 \mathrm{~cm}^{-1}, 8.5$ origin Gaussian fitting was used for peak separation. The resolved peaks, included the stretching bands of $-\mathrm{OH}$ at 3,540 and $3,340 \mathrm{~cm}^{-1}, \mathrm{C}=\mathrm{O}$ of carboxylic acid $(\mathrm{COOH})$

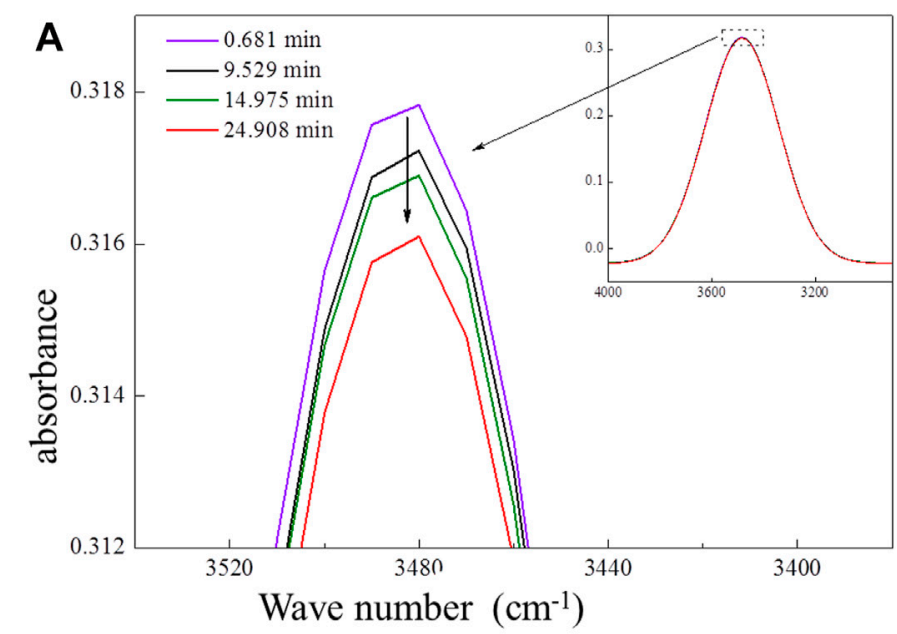

$3480 \mathrm{~cm}^{-1}$

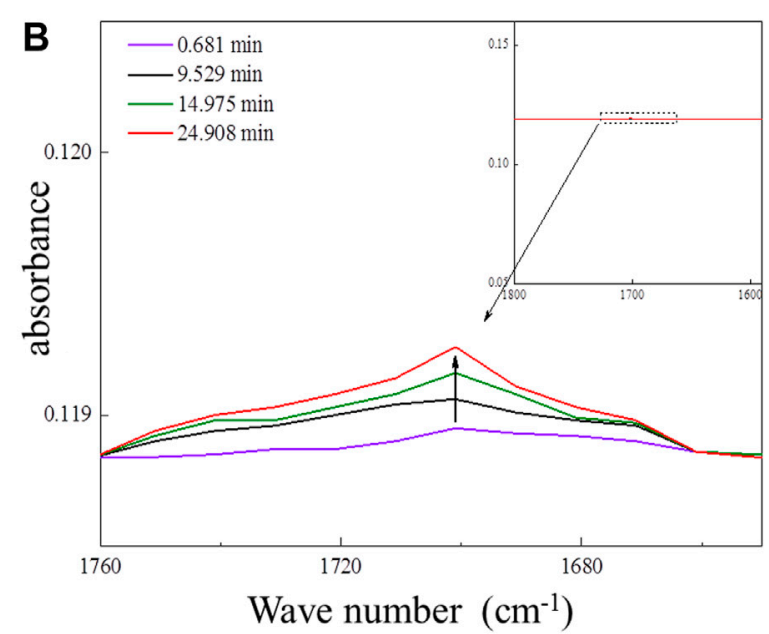

$1700 \mathrm{~cm}^{-1}$

FIGURE 4 | Changes of the AME absorption peak at 3,480 and $1700 \mathrm{~cm}^{-1}$ in the course of reactions. (A) $3,480 \mathrm{~cm}^{-1}$ (B) $1700 \mathrm{~cm}^{-1}$. 


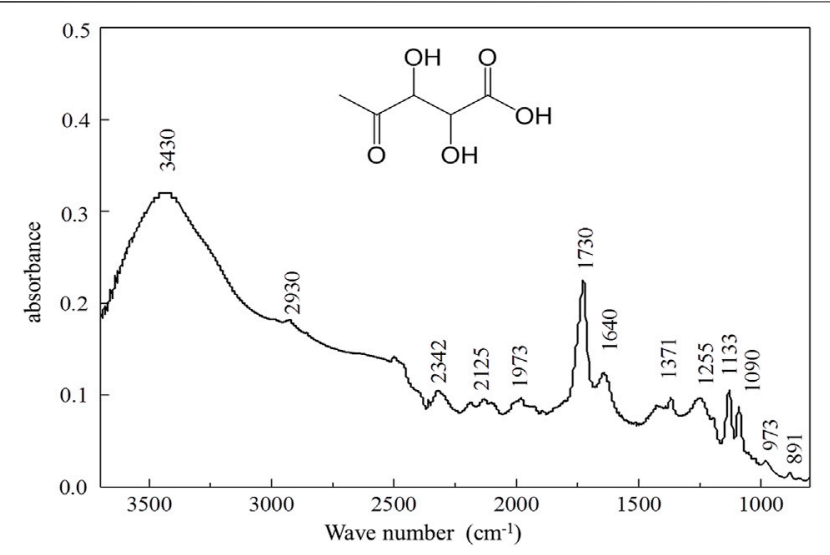

FIGURE 5 | Infrared absorption spectrum of DHOPA at room temperature.

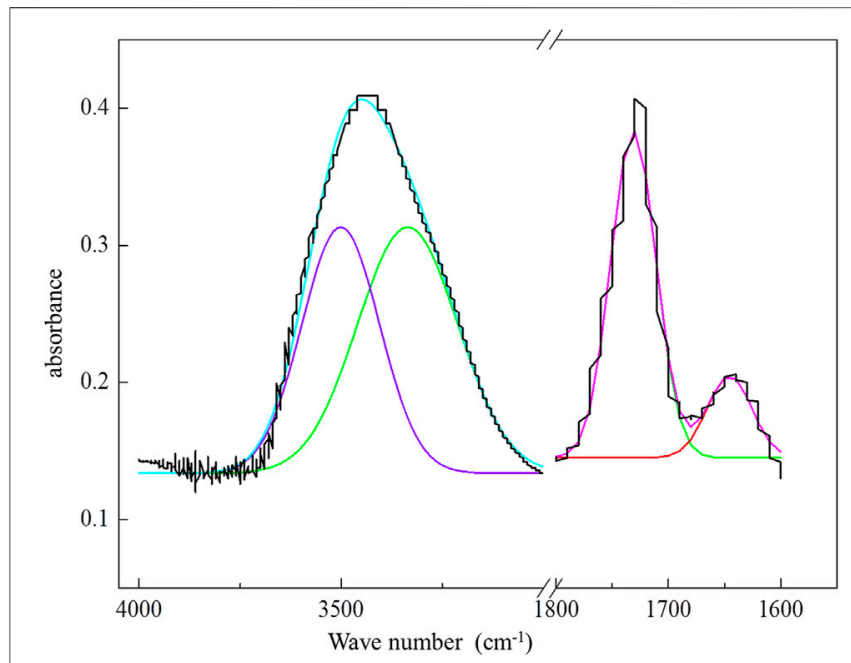

FIGURE 6 | Gaussian fitting results of DHOPA in the 4,000-3,000 and $1800-1,600 \mathrm{~cm}^{-1}$ region.

and of ketone at 1730 and $1,640 \mathrm{~cm}^{-1}$ respectively as shown in Figure 6. A comprehensive interpretation of FTIR spectra was tabulated in Table 2, which summarized the detailed assignment of spectral bands for DHOPA.

The heterogeneous oxidations of DHOPA and ozone were carried out in a reaction chamber of FTIR. The FTIR spectra of the DHOPA were monitored with time as the reactions processed. The results showed that the area of the absorption peak at wavenumber $1640 \mathrm{~cm}^{-1}(\mathrm{C}=\mathrm{O}$ stretching $)$ decreased with time when exposed to ozone, as shown in Figure 7A. Furthermore, the appearance of a small absorption peak at $3,340 \mathrm{~cm}^{-1}$ and the increase of this peak area with time were observed, as shown in Figure 7B. It was likely the infrared absorption caused by the $\mathrm{O}-\mathrm{H}$ stretching of the reaction products. Changes in DHOPA absorption peaks at $1,640 \mathrm{~cm}^{-1}$ and at $3,340 \mathrm{~cm}^{-1}$ during the experiments indicated that $\mathrm{C}=\mathrm{O}$ of DHOPA was oxidized to $\mathrm{CO}-\mathrm{OH}$ by ozone. Because $\mathrm{COOH}$ is
TABLE 2 | IR frequencies and assignments for functional groups in DHOPA

\begin{tabular}{ll}
\hline Wavenumber $\left(\mathbf{c m}^{-\mathbf{1}} \mathbf{)}\right.$ & \multicolumn{1}{c}{ Band assignment } \\
\hline 3430 & $-\mathrm{OH}$ Stretching \\
2930 & $-\mathrm{CH}_{3}$ antisymmetric stretching \\
2342 & $\mathrm{Carbonyl}(\mathrm{C}=\mathrm{O})$ \\
1730 & Carboxylic acid $(\mathrm{COOH})$ \\
1640 & $\mathrm{Carbonyl}(\mathrm{C}=\mathrm{O})$ \\
1371 & $-\mathrm{CH}_{3}$ symmetric stretching \\
1255 & $-\mathrm{OH}$ in-plane \\
1133 & $\mathrm{C}-\mathrm{C}$ Stretching \\
1090 & $\mathrm{C}-\mathrm{O}$ Stretching \\
973 & Deformation of C-H \\
884 & $\mathrm{C}-\mathrm{H}$ Deformation
\end{tabular}

more stable than $\mathrm{C}=\mathrm{O}$, the most reasonable product is 2,3 , 4trihydroxyvaleric acid. Based on the evolution in the absorption peak area at 1,640 and $3,340 \mathrm{~cm}^{-1}$ with time, the change rates of peak areas were calculated as -0.00191 int.abs/s and 0.00218 int.abs/s, respectively.

\section{Determination of Uptake Coefficient and Reaction Rate}

Figure 8 showed the standard curve of the number of AME molecules vs. the characteristic absorption peak area of AME at $3,480 \mathrm{~cm}^{-1}$. The equation was $y=6.95 \times 10^{16} x=2.57 \times 10^{19}$ with the correlation coefficient of 0.9805 . Figure 9 showed the standard curve of the number of DHOPA molecules vs. the characteristic absorption peak area of DHOPA at $1,640 \mathrm{~cm}^{-1}$. The equation was $y=4.51 \times 10^{16} x=5.33 \times 10^{18}$, and the correlation coefficient was 0.9783 .

Based on the change rate of the absorption peak area $\left(-0.00134\right.$ int.abs/s at $\left.3,480 \mathrm{~cm}^{-1}\right)$ obtained in Ozone Oxidation of $A M E$, the calculated change rate of number of AME molecules was $-9.313 \times 10^{13}$ molecules $\cdot \mathrm{s}^{-1}$ according to the standard curve shown in Figure 8. In the same way, with the change rate of DHOPA peak area at $1,640 \mathrm{~cm}^{-1}(-0.00191$ int.abs/s), the calculated change rate of number of DHOPA molecules was $-8.614 \times 10^{13}$ molecules $\cdot \mathrm{s}^{-1}$. Under the pseudofirst order reaction of this study, the uptake coefficients $\gamma$ and the pseudo-first-order reaction rate constants $k_{a p p}$ could be calculated using the change rates of the absorption peak areas at $3,480 \mathrm{~cm}^{-1}$ of AME and 1,640 $\mathrm{cm}^{-1}$ of DHOPA based on Eqs 2, 3, using the surface area of the reaction chamber of $20 \mathrm{~cm}^{-1}$ as the specific surface area for collision, the concentration of ozone of $20 \mathrm{ppm}$ and the average rate of ozone of $115 \mathrm{ml} / \mathrm{min}$. The pseudo-firstorder reaction rate constant $k_{a p p}$ were $1.89 \times 10^{-8} \mathrm{~s}^{-1}$ and $2.12 \times$ $10^{-7} \mathrm{~s}^{-1}$, and the uptake coefficients of ozone on the surface of AME and DHOPA were $(1.3 \pm 0.8) \times 10^{-8}$ and $(4.5 \pm 2.7) \times 10^{-8}$, respectively.

This experiment is the first time to study the uptake coefficient of AME and DHOPA, so we find the data of ozone heterogeneous oxidation of some other organic substances for comparison. Table 3 summarized the uptake coefficients of ozone on the surface of organic compounds reported in the literature and obtained in this study. It clearly showed that the uptake 


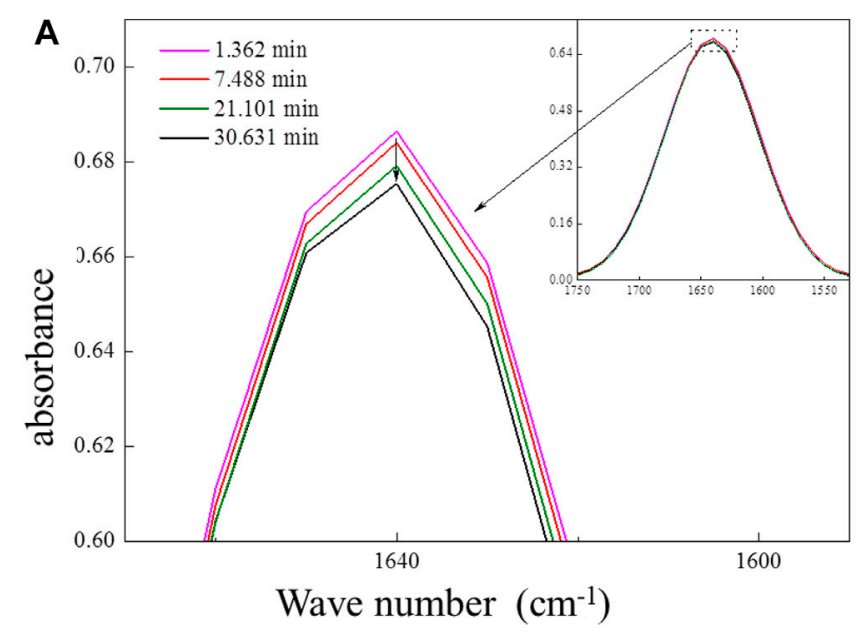

$1640 \mathrm{~cm}^{-1}$

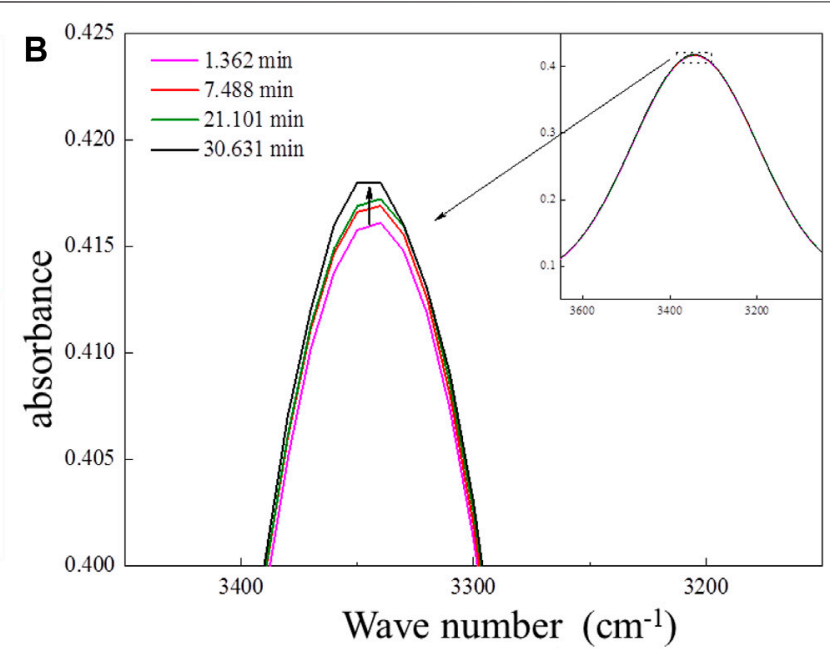

$3340 \mathrm{~cm}^{-1}$

FIGURE 7 | Changes of the DHOPA absorption peak at 1,640 and $3,340 \mathrm{~cm}^{-1}$ in the course of reactions. (A) $1,640 \mathrm{~cm}^{-1}$ (B) $3,340 \mathrm{~cm}^{-1}$.

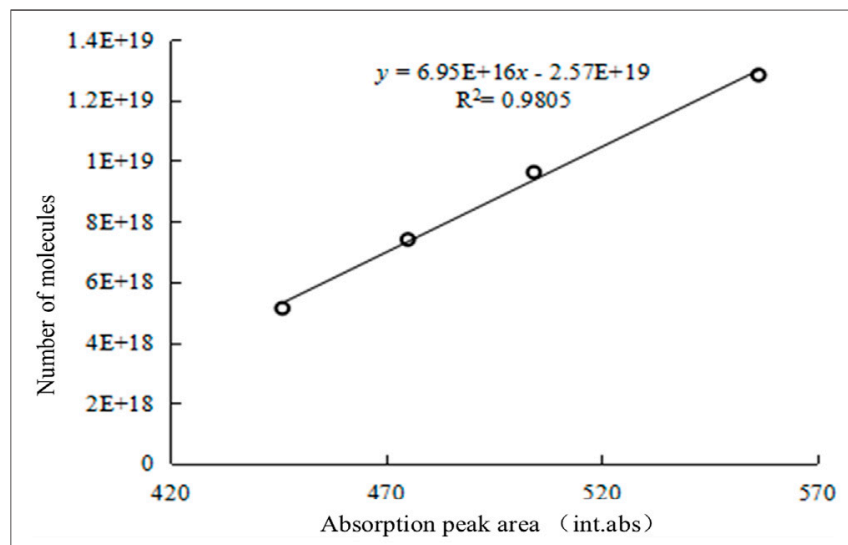

FIGURE 8 | Standard curve of number of AME molecules vs. absorption peak area at $3,480 \mathrm{~cm}^{-1}$.

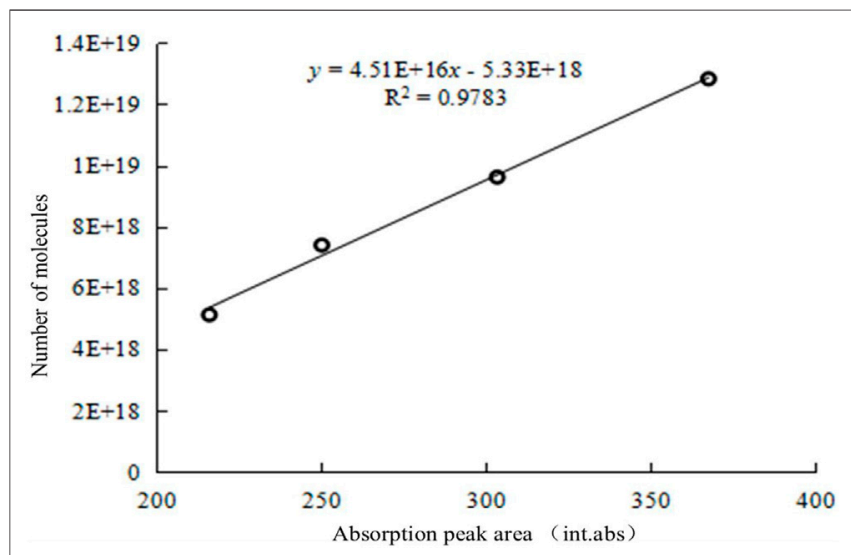

FIGURE 9 | Standard curve of number of DHOPA molecules vs. absorption peak area at $1,640 \mathrm{~cm}^{-1}$.
TABLE 3 | Uptake coefficients of ozone on surface of organic matters.

\begin{tabular}{llcl} 
Reactants & $\begin{array}{c}\text { concentration } \\
\left(\mathbf{O}_{\mathbf{3}}\right)\end{array}$ & $\begin{array}{c}\text { Uptake } \\
\text { coefficient } \mathbf{(} \boldsymbol{\gamma})\end{array}$ & \multicolumn{1}{c}{ Reference } \\
\hline AME & $20 \mathrm{ppm}$ & $(1.3 \pm 0.8) \times 10^{-8}$ & This work \\
DHOPA & $20 \mathrm{ppm}$ & $(4.5 \pm 2.7) \times 10^{-8}$ & This work \\
Oleic acid & $200 \mathrm{ppb}$ & $(5 \pm 3) \times 10^{-4}$ & Hartz et al. (2007) \\
Oleic acid & $90 \mathrm{ppm}$ & $(7.5 \pm 1.2) \times 10^{-4}$ & Hearn and Smith (2004) \\
Linoleic acid & $90 \mathrm{ppm}$ & $(1.1 \pm 0.2) \times 10^{-3}$ & Hearn and Smith (2004) \\
Cholesterol & $200 \mathrm{ppb}$ & $5 \times 10^{-4}$ & Hartz et al. (2007) \\
Cholesterol & $2 \mathrm{ppm}$ & $(2.8 \pm 0.4) \times 10^{-6}$ & Dreyfus et al. (2005) \\
Fatty acid & $200 \mathrm{ppb}$ & $(2.08 \pm 0.04) \times 10^{-5}$ & Hartz et al. (2007) \\
Adipic acid & $200 \mathrm{ppb}$ & $(1.67 \pm 0.08) \times 10^{-5}$ & Hartz et al. (2007) \\
Oleyl alcohol & $90 \mathrm{ppm}$ & $7.5 \times 10^{-4}$ & Hearn and Smith (2004) \\
Caprylic & $200 \mathrm{ppb}$ & $(1.08 \pm 0.07) \times 10^{-5}$ & Hartz et al. (2007) \\
acid & & &
\end{tabular}

coefficients of ozone on AME and DHOPA were quite different from other organic compounds, which were 2-5 orders of magnitude lower than those of oleic acid, linoleic acid, and cholesterol, as well as no significant correlation with ozone concentration.

\section{CONCLUSION}

In this study, in-situ FTIR was utilized to study the heterogeneous oxidations of two secondary organic tracers (AME and DHOPA) by ozone. Under the condition of $20 \mathrm{ppm}$ ozone exposure for $30 \mathrm{~min}$, the heterogeneous oxidations of AME and DHOPA by ozone were carried out in a reaction chamber of FTIR at a room temperature of $25^{\circ} \mathrm{C}$ and $30 \%$ relative humidity. The results showed that the AME absorption peak area at $3,480 \mathrm{~cm}^{-1}$ (-OH stretching) decreased while a small absorption peak area increased at $1700 \mathrm{~cm}^{-1}$ during ozone passing over the AME solid powder. Such changes indicated that-OH, at the end chain of 
AME, was oxidized to $\mathrm{C}=\mathrm{O}$ bond by ozone. For DHOPA, the absorption peak area at $1,640 \mathrm{~cm}^{-1}$ (Carbonyl $\mathrm{C}=\mathrm{O}$ stretching) decreased while a small absorption peak area increased at $3,340 \mathrm{~cm}^{-1}$ during the ozone oxidation. It was likely the infrared absorption caused by the $\mathrm{O}-\mathrm{H}$ stretching of the reaction products. Based on the changes in the absorption peak area at 3,480 and $1700 \mathrm{~cm}^{-1}$ of AME, as well as the changes at 1,640 and $3,340 \mathrm{~cm}^{-1}$ of DHOPA, the change rates of peak areas were calculated as -0.00134 and 0.00117 int.abs/s for AME, as well as -0.00191 and 0.00218 int.abs/s for DHOPA, respectively. The pseudo-first-order reaction rate constant $k_{a p p}$ were $1.89 \times 10^{-8} \mathrm{~s}^{-1}$ and $2.12 \times 10^{-7} \mathrm{~s}^{-1}$, and the uptake coefficients of ozone on the surface of AME and DHOPA were $(1.3 \pm 0.8) \times 10^{-8}$ and $(4.5 \pm 2.7) \times 10^{-8}$, respectively.

The oxidation rates of AME and DHOPA were found to be relatively slow compared with those of the primary organic tracers reported in previous literature, even exposed to relative high ozone concentrations. It indicates that AME and DHOPA could be reactive, but the oxidation processes would be so slow that the changes of AME and DHOPA due to ozone oxidation are negligible. Therefore, under the atmospheric conditions with ozone as the main oxidant, AME and DHOPA, the secondary organic tracers of isoprene and toluene respectively, can be considered the source contribution estimated on the basis of the tracer methods are reliable. In this paper, the heterogeneous

\section{REFERENCES}

And, J., and Smith, G. D. (2004). Kinetics and Product Studies for Ozonolysis Reactions of Organic Particles Using Aerosol CIMS [J]. The J. Phys. Chem. A 108 (445), 10019-10029.

Branca, C., D’Angelo, G., Crupi, C., Khouzami, K., Rifici, S., Ruello, G., et al. (2016). Role of the $\mathrm{OH}$ and $\mathrm{NH}$ Vibrational Groups in PolysaccharideNanocomposite Interactions: A FTIR-ATR Study on Chitosan and Chitosan/clay Films. Polymer 99, 614-622. doi:10.1016/ j.polymer.2016.07.086

Ding, X., Wang, X. M., and Gao, B. (2012). Tracer-Based Estimation of Secondary Organic Carbon in the Pearl River Delta, South China [J]. J. Geophys. Res. Atmospheres 117 (D5), 313. doi:10.1029/2011jd016596

Dreyfus, M. A., Tolocka, M. P., Dodds, S. M., Dykins, J., and Johnston, M. V. (2005). Cholesterol Ozonolysis: Kinetics, Mechanism, and Oligomer Products. J. Phys. Chem. A. 109 (28), 6242-6248. doi:10.1021/jp050606f

Engelke, U. F. H., Zijlstra, F. S. M., Mochel, F., Valayannopoulos, V., Rabier, D., Kluijtmans, L. A. J., et al. (2010). Mitochondrial Involvement and Erythronic Acid as a Novel Biomarker in Transaldolase Deficiency. Biochim. Biophys. Acta (Bba) - Mol. Basis Dis. 1802 (11), 1028-1035. doi:10.1016/ j.bbadis.2010.06.007

Gao, X., Leng, C., Zeng, G., Fu, D., Zhang, Y., and Liu, Y. (2019). Ozone Initiated Heterogeneous Oxidation of Unsaturated Carboxylic Acids by ATR-FTIR Spectroscopy. Spectrochimica Acta A: Mol. Biomol. Spectrosc. 214, 177-183. doi:10.1016/j.saa.2019.02.025

Ge, S., Xu, Y., and Jia, L. (2016). Secondary Organic Aerosol Formation from Ethyne in the Presence of $\mathrm{NaCl}$ in a Smog Chamber. Environ. Chem. 13 (4), 699-710. doi:10.1071/en15155

Goldstein, D. N., Mccormick, J. A., and George, S. M. (2008). Al2O3 Atomic Layer Deposition with Trimethylaluminum and Ozone Studied by In Situ Transmission FTIR Spectroscopy and Quadrupole Mass Spectrometry. J. Phys. Chem. C 112 (49), 19530-19539. doi:10.1021/ jp804296a oxidation of secondary organic tracers in ozone environment was discussed. The heterogeneous oxidation of organic tracers by different oxidants needs to be studied more comprehensively in the future.

\section{DATA AVAILABILITY STATEMENT}

The original contributions presented in the study are included in the article/Supplementary Material, further inquiries can be directed to the corresponding author.

\section{AUTHOR CONTRIBUTIONS}

RW Participate in experiments and write this paper $\mathrm{YH}$ Participate in experiments QH Participate in experiments GC Support and guide experiments RZ Guide experiments.

\section{FUNDING}

This study was financially supported by the National Natural Science Foundation of China (21876036) and the Fund for the Research and Development of Science and Technology in Shenzhen (JCYJ20150625142543472, ZDSYS201603301417588).

Hartz, K., Weitkamp, E. A., Sage, A. M., Donahue, N. M., and Robinson, A. L. (2007). Laboratory Measurements of the Oxidation Kinetics of Organic Aerosol Mixtures Using a Relative Rate Constants Approach[J]. J. Geophys. Res. 112 (D4), 204. doi:10.1029/2006jd007526

He, X., Leng, C. B., and Zhang, Y. H. (2016). A Comparison of Heterogeneous Reaction Kinetics of Oleic Acid Thin Film and Oleic Acid Coated Flyash with Ozone Using Vacuum FTIR. Guang Pu Xue Yu Guang Pu Fen Xi 36 (5), 1576-1580.

He, X., and Zhang, Y.-H. (2019). Influence of Relative Humidity on SO2 Oxidation by $\mathrm{O} 3$ and NO2 on the Surface of TiO2 Particles: Potential for Formation of Secondary Sulfate Aerosol. Spectrochimica Acta Part A: Mol. Biomol. Spectrosc. 219, 121-128. doi:10.1016/j.saa.2019.04.046

Hearn, J. D., and Smith, G. D. (2004). Kinetics and Product Studies for Ozonolysis Reactions of Organic Particles Using Aerosol CIMS. J. Phys.Chem. A. 108, 10,019-10,029. doi:10.1021/jp0404145

Hennigan, C. J., Sullivan, A. P., Collett, J., and Robinson, A. L. (2010). Levoglucosan Stability in Biomass Burning Particles Exposed to Hydroxyl Radicals [J]. Geophys. Res. Lett. 37 (L09), 806. doi:10.1029/2010gl043088

Hoffmann, D., Tilgner, A., Iinuma, Y., and Herrmann, H. (2010). Atmospheric Stability of Levoglucosan: A Detailed Laboratory and Modeling Study. Environ. Sci. Technol. 44, 694-699. doi:10.1021/es902476f

Hudson, P. K., Foster, K. L., Tolbert, M. A., George, S. M., Carlo, S. R., and Grassian, V. H. (2001). HBr Uptake on Ice: Uptake Coefficient, $\mathrm{H} 2 \mathrm{O} / \mathrm{HBr}$ Hydrate Formation, and H2O Desorption Kinetics. J. Phys. Chem. A. 105 (4), 694-702. doi:10.1021/jp002700w

Hung, H.-M., Katrib, Y., and Martin, S. T. (2005). Products and Mechanisms of the Reaction of Oleic Acid with Ozone and Nitrate Radical. J. Phys. Chem. A. 109 (20), 4517-4530. doi:10.1021/jp0500900

Hung, H.-M., and Tang, C.-W. (2010). Effects of Temperature and Physical State on Heterogeneous Oxidation of Oleic Acid Droplets with Ozone. J. Phys. Chem. A. 114 (50), 13104-13112. doi:10.1021/jp105042w

Injae, K., Hong, J., Chung, Y., Jeongchil, S., Dongyoung, K., Dongyoon, S., et al. (1998). Statistical Analysis on Deviation of Radial Composition by Measuring FTIR for Hg1-xCdxTe [J]. Ungyong Mulli 11 (1), S38-S42. 
Jaoui, M., Kleindienst, T. E., Lewandowski, M., and Edney, E. O. (2004). Identification and Quantification of Aerosol Polar Oxygenated Compounds Bearing Carboxylic or Hydroxyl Groups. 1. Method Development. Anal. Chem. 76 (16), 4765-4778. doi:10.1021/ac049919h

Katrib, Y., Biskos, G., Buseck, P. R., Davidovits, P., Jayne, J. T., Mochida, M., et al. (2005). Ozonolysis of Mixed Oleic-Acid/Stearic-Acid Particles: Reaction Kinetics and Chemical Morphology. J. Phys. Chem. A. 109 (48), 10910-10919. doi:10.1021/jp054714d

Kessler, S. H., Smith, J. D., Che, D. L., Worsnop, D. R., Wilson, K. R., and Kroll, J. H. (2010). Chemical Sinks of Organic Aerosol: Kinetics and Products of the Heterogeneous Oxidation of Erythritol and Levoglucosan. Environ. Sci. Technol. 44 (18), 7005-7010. doi:10.1021/ es $101465 \mathrm{~m}$

Kleindienst, T. E., Jaoui, M., Lewandowski, M., Offenberg, J. H., Lewis, C. W., Bhave, P. V., et al. (2007). Estimates of the Contributions of Biogenic and Anthropogenic Hydrocarbons to Secondary Organic Aerosol at a southeastern US Location. Atmos. Environ. 41 (37), 8288-8300. doi:10.1016/ j.atmosenv.2007.06.045

Lai, C., Liu, Y., Ma, J., Ma, Q., and He, H. (2014). Degradation Kinetics of Levoglucosan Initiated by Hydroxyl Radical under Different Environmental Conditions. Atmos. Environ. 91 (054), 32-39. doi:10.1016/ j.atmosenv.2014.03.054

Lambe, A. T., Miracolo, M. A., Hennigan, C. J., Robinson, A. L., and Donahue, N. M. (2009). Effective Rate Constants and Uptake Coefficients for the Reactions of Organic Molecular Markers (N-Alkanes, Hopanes, and Steranes) in Motor Oil and Diesel Primary Organic Aerosols with Hydroxyl Radicals. Environ. Sci. Technol. 43 (23), 8794-8800. doi:10.1021/es901745h

Lambe, A. T., Onasch, T. B., Croasdale, D. R., Wright, J. P., Martin, A. T., Franklin, J. P., et al. (2012). Transitions from Functionalization to Fragmentation Reactions of Laboratory Secondary Organic Aerosol (SOA) Generated from the $\mathrm{OH}$ Oxidation of Alkane Precursors. Environ. Sci. Technol. 46 (10), 5430-5437. doi:10.1021/es300274t

Lee, S.-Y., and Harris, M. T. (2006). Surface Modification of Magnetic Nanoparticles Capped by Oleic Acids: Characterization and Colloidal Stability in Polar Solvents. J. Colloid Interf. Sci. 293 (2), 401-408. doi:10.1016/j.jcis.2005.06.062

Lee, S., Jang, M., and Kamens, R. M. (2004). SOA Formation from the Photooxidation of a-pinene in the Presence of Freshly Emitted Diesel Soot Exhaust. Atmos. Environ. 38 (16), 2597-2605. doi:10.1016/ j.atmosenv.2003.12.041

Lelièvre, S., Bedjanian, Y., Pouvesle, N., Delfau, J.-L., Vovelle, C., and Le Bras, G. (2004). Heterogeneous Reaction of Ozone with Hydrocarbon Flame Soot. Phys. Chem. Chem. Phys. 6 (6), 1181-1191. doi:10.1039/b316895f

Luo, Z., Lin, X. Y., Lin, S. H., Yu, C. H., Lin, K. X., Yu, Y. P., et al. (2003). Infrared Analysis on Hydrogen Content and Si-H Bonding Configurations of Hydrogenated Amorphous Silicon Films. Acta Physica Sinica 52 (1), 169-174. doi:10.7498/aps.52.169

Moise, T., and Rudich, Y. (2002). Reactive Uptake of Ozone by Aerosol-Associated Unsaturated Fatty Acids: Kinetics, Mechanism, and Products. J. Phys. Chem. A. 106 (27), 6469-6476. doi:10.1021/jp025597e

Nash, D. G., Tolocka, M. P., and Baer, T. (2006). The Uptake of O3by Myristic Acid-Oleic Acid Mixed Particles: Evidence for Solid Surface Layers. Phys. Chem. Chem. Phys. 8 (38), 4468-4475. doi:10.1039/b609855j

Nieto-Gligorovski, L., Net, S., Gligorovski, S., Zetzsch, C., Jammoul, A., D’Anna, B., et al. (2008). Interactions of Ozone with Organic Surface Films in the Presence of Simulated Sunlight: Impact on Wettability of Aerosols. Phys. Chem. Chem. Phys. 10 (20), 2964-2971. doi:10.1039/b717993f

Rosen, E. P., Garland, E. R., and Baer, T. (2008). Ozonolysis of Oleic Acid Adsorbed to Polar and Nonpolar Aerosol Particles. J. Phys. Chem. A. 112 (41), 10315-10324. doi:10.1021/jp8045802

Seisel, S., Keil, T., Lian, Y., and Zellner, R. (2006). Kinetics of the Uptake of SO2 on mineral Oxides: Improved Initial Uptake Coefficients at $298 \mathrm{~K}$ from Pulsed
Knudsen Cell Experiments. Int. J. Chem. Kinet. 38 (4), 242-249. doi:10.1002/ kin. 20148

Smith, G. D., Woods, E., Deforest, C. L., Baer, T., and Miller, R. E. (2002). Reactive Uptake of Ozone by Oleic Acid Aerosol Particles: Application of Single-Particle Mass Spectrometry to Heterogeneous Reaction Kinetics. J. Phys. Chem. A. 106 (35), 8085-8095. doi:10.1021/jp020527t

Thornberry, T., and Abbatt, J. P. D. (2004). Heterogeneous Reaction of Ozone with Liquid Unsaturated Fatty Acids: Detailed Kinetics and Gas-phase Product Studies. Phys. Chem. Chem. Phys. 6 (1), 84-93. doi:10.1039/ b310149e

Wang, R. H., Huang, Y. J., and Cao, G. (2020). Heterogeneous Oxidation of Isoprene SOA and Toluene SOA Tracers by Ozone. Chemosphere 249, 126258.

Weitkamp, E. A., Hartz, K. E. H., Sage, A. M., Donahue, N. M., and Robinson, A. L. (2008a). Laboratory Measurements of the Heterogeneous Oxidation of Condensed-phase Organic Molecular Makers for Meat Cooking Emissions. Environ. Sci. Technol. 42 (14), 5177-5182. doi:10.1021/es800181b

Weitkamp, E. A., Lambe, A. T., Donahue, N. M., and Robinson, A. L. (2008b). Laboratory Measurements of the Heterogeneous Oxidation of Condensed-phase Organic Molecular Makers for Motor Vehicle Exhaust. Environ. Sci. Technol. 42 (21), 7950-7956. doi:10.1021/ es $800745 x$

Weitkamp, E. A., Sage, A. M., Pierce, J. R., Donahue, N. M., and Robinson, A. L. (2007). Organic Aerosol Formation from Photochemical Oxidation of Diesel Exhaust in a Smog Chamber. Environ. Sci. Technol. 41 (20), 6969-6975. doi:10.1021/es070193r

Worsnop, D. R., Morris, J. W., Shi, Q., Davidovits, P., and Kolb, C. A. (2002). A Chemical Kinetic Model for Reactive Transformations of Aerosol Particles [J]. Geophys. Res. Lett. 29 (20), 571-574. doi:10.1029/2002gl015542

Xu, R., Lam, H. K., Wilson, K. R., Davies, J. F., Song, M., Li, W., et al. (2020). Effect of Inorganic-To-Organic Mass Ratio on the Heterogeneous OH Reaction Rates of Erythritol: Implications for Atmospheric Chemical Stability of 2methyltetrols. Atmos. Chem. Phys. 20 (6), 3879-3893. doi:10.5194/acp-203879-2020

Zeng, G., Holladay, S., Langlois, D., Zhang, Y., and Liu, Y. (2013). Kinetics of Heterogeneous Reaction of Ozone with Linoleic Acid and its Dependence on Temperature, Physical State, RH, and Ozone Concentration. J. Phys. Chem. A. 117 (9), 1963-1974. doi:10.1021/jp308304n

Zhou, L., Wang, W., Gai, Y., and Ge, M. (2014). Knudsen Cell and Smog Chamber Study of the Heterogeneous Uptake of Sulfur Dioxide on Chinese mineral Dust. JOURNAL ENVIRONMENTAL SCIENCES 26 (12), 2423-2433. doi:10.1016/ j.jes.2014.04.005

Ziemann, P. J. (2005). Aerosol Products, Mechanisms, and Kinetics of Heterogeneous Reactions of Ozone with Oleic Acid in Pure and Mixed Particles. Faraday Discuss. 130, 469-490. doi:10.1039/b417502f

Conflict of Interest: The authors declare that the research was conducted in the absence of any commercial or financial relationships that could be construed as a potential conflict of interest.

Publisher's Note: All claims expressed in this article are solely those of the authors and do not necessarily represent those of their affiliated organizations, or those of the publisher, the editors and the reviewers. Any product that may be evaluated in this article, or claim that may be made by its manufacturer, is not guaranteed or endorsed by the publisher.

Copyright (c) 2021 Wang, Huang, Hu, Cao and Zhu. This is an open-access article distributed under the terms of the Creative Commons Attribution License (CC BY). The use, distribution or reproduction in other forums is permitted, provided the original author(s) and the copyright owner(s) are credited and that the original publication in this journal is cited, in accordance with accepted academic practice. No use, distribution or reproduction is permitted which does not comply with these terms. 